\title{
Letter to Editor: Climate Change and Waterborne Diseases
}

\author{
ditation: Farrokhi M. Climate Change and Waterborne Diseases. Health in Emergencies and Disasters Quarterly. 2016; 1(4):175-176. https:// \\ doi.org/10.18869/nrip.hdq.1.4.175
}

: https://doi.org/10.18869/nrip.hdq.1.4.175

For sustainable development, an integrated cost-effective approach focused on health and environmental protection is necessary. Disaster risk reduction (DRR) is increasingly recognized as a major factor in achieving sustainable development; however, the systematic integration of DRR into development planning and activities has remained a challenge [1].

$\mathrm{CO}_{2}$ and other greenhouse gases are causing climate change. Some projected impacts of climate change such as global warming, desertification, rising sea levels, and average temperature might have a disproportionate impact on countries, especially on developing ones which least contributed to the cause of climate change [2].

The top ten hazards in recent years are all weather and climate related and many climate-related disasters such as floods, drought, heat waves, and dust storm are increasing around the world [3].

Climate change policies, such as those featured in the Paris Agreement, are grounded in the arenas of scientific and technical information. The reports of the Intergovernmental Panel on Climate Change (IPCC) emphasize, understandably, the scientific and technical aspects of climate change. This emphasize is closely similar to the motto of Sendai framework. The Sendai Framework for Disaster Risk Reduction 2015-2030 is the first major agreement of the post-2015 development agenda, with 7 targets and 4 priorities for action. The motto of Sendai frame work is Disaster Risk Understanding.

United Nation International Strategy for Disaster Reduction (UNISDR) reports that climate change will affect all communities in 4 key sectors: water, food, industry-economy, and health. In 2006, WHO released a report entitled "preventing disease through healthy environment". In 2008, WHO motto was protecting health from climate change reflecting the importance of this phenomenon in health. In that time, WHO considered climate change as an important environmental risk factor to estimate global burden of disease. WHO estimates that $80 \%$ of all health problems in the world are attributable to inadequate water supply or sanitation. Infections related to water may be classified into 4 main groups; waterborne diseases, water-washed diseases, waterbased diseases, and water-related diseases [4].

Waterborne disease is where a pathogen is transmitted by ingestion of contaminated water. Waterborne diseases may include gastroenteritis caused by coccidian protozoans (Cryptosporidium parvum, Cyclospora cayetanensis, Isospora belli), Hepatitis A virus, astroviruses, caliciviruses, Giardia lamblia, the non-cholera marine Vibrios (Vibrio vulnificus, Vibrio parahaemolyticus), Campylobacter jejuni, Shigella spp., and the typhoidal and nontyphoidal Salmonella species. Humans may be exposed to these agents following the consumption of contaminated drinking water or by direct exposure such as swimming or showering [5].

One of the most important effects of climate change on public health may be increasing the waterborne disease out breaks. The potential increase in such conditions may suggest an increased demand on emergency medicine responses particularly in highly vulnerable areas.

It is predicted that the number of rainy days will decrease, but the average volume of each rainfall event will increase. Therefore, climate change means that some regions will experience an increase in rainfall and flood risk, while regions that are prone to droughts may experience more extreme droughts. On the other hand, the average temperature is predicted to increase. Both flooding and drought will affect water quality and consequently increase waterborne illnesses [6].

Floods can increase human exposure to pathogens, as contaminants are spread by floodwaters and runoff. Water treatment facilities can get damaged, which can result in the distribution of untreated or insufficient treated water. Sewer and water pipes can break, which can lead to contamination of drinking water with sewage. Floods can also transport fecal matter from the ground or sewers that have overflowed, and contaminate wells, boreholes, and surface waters.

Droughts can increase concentrations of effluent pathogens, overwhelming water treatment plants and thus 
contaminating surface water and groundwater. Groundwater is the main resource for water supply in rural communities in Iran and contaminated groundwater can be the major reason for waterborne diseases outbreaks. The wastewater discharging as well as drought by reducing groundwater table levels, are the main causes of groundwater contamination in Iran in recent years [1].

Many studies show that increase in water temperature, heavy rains, floods, and droughts will increase the distribution and patterns of human exposures to pathogens. Several outbreaks of water borne diseases have been reported due to groundwater contamination by pathogens as a consequence of drought that has lowered the water table, resulting in changes in groundwater flows of surface water into groundwater [6].

The World Health Organization estimates that there are approximately 4 billion cases of diarrhea each year, and 2.2 million deaths resulting from diarrheal illnesses. This means that, if the average global temperature was to increase by one degree, there could be an additional 320 million cases and 176000 deaths from diarrheal illnesses.

With regard to above mentioned issues, many countries are improving their ability to cope with health impacts of climate change and enhancing their early warning systems, vulnerability assessment, and response plan to emergencies. Nowadays, risk of water borne illnesses outbreaks from climate change needs more collaboration among all organizations working in disaster risk reduction and climate change needs to be more comprehensively addressed in DRR tools.

We need more coordinated approach among different organizations such as environmental protection, public health, agricultural and veterinary medicine, water management, and other utilities sectors to protect water safety against climate change effects.

* Corresponding Author:

Mehrdad Farrokhi, PhD

Address: Department of Health in Disasters and Emergencies,

Research Center in Disaster and Emergencies Health, University of Social Welfare and Rehabilitation Sciences, Kodakyar Ave., Daneshjo St., Evin, Tehran, Iran.

E-mail:farrokhi@gums.ac.ir funding priorities in wastewater project in rural communities in the Islamic Republic of Iran. Water Science and Technology. 2008; 58(6):1181-186.

[2] World Health Organization. Water-related diseases: Diarrhoea. Geneva: World Health Organization; 2007.

[3] Economic Commission for Latin America and the Caribbean. Handbook for Estimating the Socio-Economic and Environmental Effects of Disasters. Santiago: Economic Commission for Latin America and the Caribbean; 2003.

[4] World Health Organization. Quantification of the disease burden attributable to environmental risk factors. Geneva: World Health Organization; 2011.

[5] Hernández-Delgado EA. The emerging threats of climate change on tropical coastal ecosystem services, public health, local economies and livelihood sustainability of small islands: Cumulative impacts and synergies. Marine Pollution Bulletin. 2015; 101(1):5-28.

[6] Funari E, Manganelli M, Sinisi L. Impact of climate change on waterborne diseases. Annali dell'Istituto Superiore di Sanità. 2012; 48(4):473-87.

\section{References}

[1] Farrokhi M, Hajrasoliha M, Meemari G, Fahiminia M, Talebi M, Kohansal M. The creation of management systems for 